UNIVERSIDADE DE BRASÍLIA

Faculdade de Educação - UAB/UnB/MEC/SECAD

Curso de Especialização em Educação na Diversidade e Cidadania, com Ênfase em EJA

\title{
A EJA NO RESGATE DA AUTOESTIMA E NA CONSTRUÇÃO DO CIDADÃO CRíTICO
}

FÚLVIA PEREIRA RUFINO

LÍVIA SILVA MOURÃO

\author{
PROFESSORA ORIENTADORA: \\ MARIA CLARISSE VIEIRA \\ TUTOR ORIENTADOR: \\ MARCO AURÉLIO BRAGA
}

PROJETO DE INTERVENÇÃO

BRASÍLIA, DF Julho/ 2010 
UNIVERSIDADE DE BRASÍLIA

Faculdade de Educação - UAB/UnB/MEC/SECAD

Curso de Especialização em Educação na Diversidade e Cidadania, com Ênfase em EJA

\section{FÚLVIA PEREIRA RUFINO \\ LÍVIA SILVA MOURÃO}

\section{A EJA NO RESGATE DA AUTOESTIMA E NA CONSTRUÇÃO DO CIDADÃO CRíTICO}

Trabalho de conclusão do Curso Especialização em Educação na Diversidade e Cidadania, com Ênfase em EJA, como parte dos requisitos necessários para obtenção do grau de Especialista na Educação de Jovens e Adultos.

PROFESSORA ORIENTADORA MARIA CLARISSE VIEIRA

TUTOR ORIENTADOR MARCO AURÉLIO BRAGA

AVALIADORA EXTERNA PROFESSORA LEILA CHALUB MARTINS

BRASÍLIA - DF, Julho/2010 


\section{AGRADECIMENTOS}

Agradecemos a Deus, aos amigos, professores, tutores e colegas que contribuíram direta e indiretamente para a realização desse Projeto. Em especial, agradecemos a Maria Madalena Silva pela colaboração, conselhos e incentivo para que pudéssemos realizar um projeto que verdadeiramente tornasse nosso aluno-trabalhador um ser resiliente.

Agradecemos também aos educadores que nos antecederam no trabalho de construção de sujeitos coletivos da diversidade na Educação de Jovens e Adultos. "Professor é pesquisador e precisa responder aos seus ancestrais," lembrou a professora Leila Chalub Martins, em nosso encontro em fevereiro de 2010. Esse curso é uma maneira de intensificarmos nosso diálogo com professores e outros pensadores que propagaram a ideia de que educação é construção coletiva e que não deve ser privilégio para ninguém. Somos todos intelectuais. 
"É preciso que saibamos que, sem certas qualidades ou virtudes como amorosidade, respeito aos outros, tolerância, humildade, gosto pela alegria, gosto pela vida, abertura ao novo, disponibilidade à mudança, persistência na luta, recusa aos fatalismos, identificação com a esperança, abertura à justiça, não é possível a prática pedagógica progressista, que não se faz somente com ciência e técnica." Paulo Freire 


\section{RESUMO}

Esse Projeto de Intervenção Local tem como objetivos: motivar e estimular os educandos que trabalham e estudam a vencerem as intempéries do dia-a-dia; contribuir para superação do saber de senso comum pelo conhecimento mais crítico e possibilitar transformações reais nas condições de vida dos alunos. Atualmente percebemos as dificuldades dos educadores e dos educandos de vencerem as adversidades da vida pessoal, escolar e profissional. Resultado da falta de percepção dos elos existentes entre os aspectos da vida do ser humano e da relação existente entre saber formal e os saberes de cada indivíduo. Para que professores e alunos possam ter atitude resiliente e responder de maneira mais consistente aos desafios encontrados, desenvolvemos trabalho pedagógico por meio do qual esperamos colaborar para a elevação da autoestima da comunidade escolar e a formação crítico-analítica. Os resultados serão obtidos ao longo do processo. A metodologia a ser utilizada será: leitura, compreensão e interpretação de diversas tipologias textuais, audição, leitura e discussão de letras de canções da Música Popular Brasileira (MPB), visionamento de filmes nacionais, desenvolvimento de dinâmicas em grupo e atividades de socialização e confraternização para motivação da autoestima e análise crítica dos temas abordados em sala de aula.Os objetivos gerais ainda não foram alcançados em sua totalidade. A equipe de educadoras está desenvolvendo as atividades, visto que trata-se de um processo contínuo.

Palavras-chave: autoestima, pensamento crítico e resiliência. 


\section{SUMÁRIO}

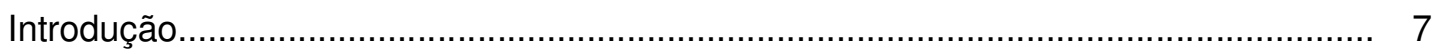

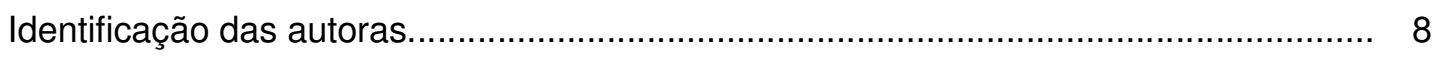

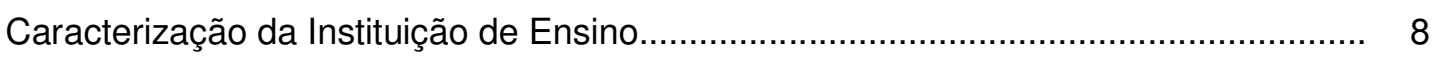

Características básicas do público-alvo.................................................................... 9

Justificativa e caracterização dos problemas........................................................... 9

Objetivos Gerais....................................................................................... 11

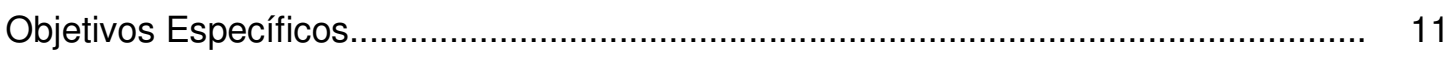

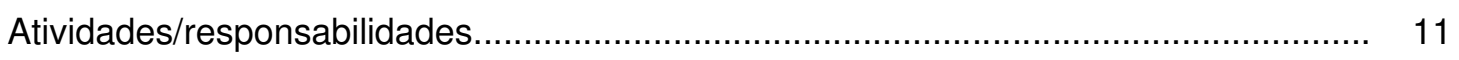

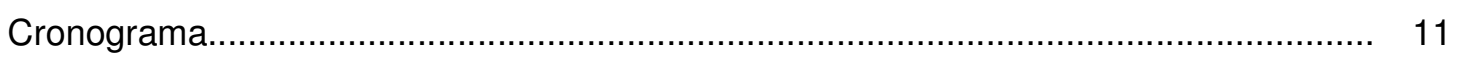

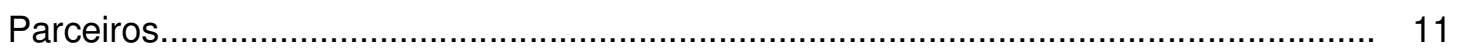

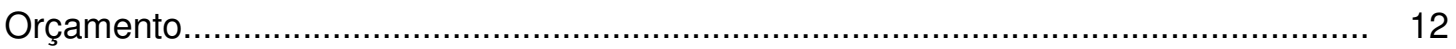

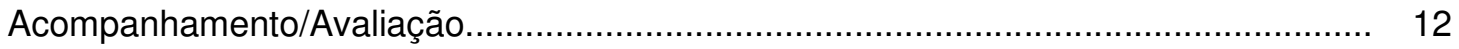

Referências Bibliográficas.............................................................................. 15

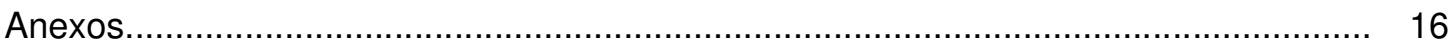




\section{INTRODUÇÃO}

A realidade da Educação de Jovens e Alunos - EJA é muito difícil. No início do ano letivo, os professores têm dificuldades para serem lotados e os alunos encontram dificuldades para efetivarem suas matrículas. Vencidas as primeiras barreiras, as salas de aulas ficam cheias. Mas, no fim do semestre, são alguns poucos "sobreviventes". Muitas são as causas da evasão escolar na EJA, mas vamos nos ater a dois pontos considerados como eixo para a confecção desse Projeto de Intervenção Local, quais sejam: falta de motivação e visão crítica pouco desenvolvida dos nossos alunos. Alguns vão à escola em busca do diploma, outros com o intuito de reverter a própria sorte. A escola precisa então acolher esse indivíduo desde a sua entrada, valorizar o que ele traz de cultura e intelecto, buscando sempre formar cidadãos críticos e motivados a mudanças significativas na própria vida.

Com o Projeto "A EJA no resgate da autoestima e na construção do cidadão crítico", almejamos que nosso aluno melhore sua autoestima, buscando novos caminhos para vencer as dificuldades que certamente encontrará, tornado-se um cidadão verdadeiramente crítico da própria realidade. 
1. Identificação das autoras

Fúlvia Pereira Rufino - turma F

QNE 8 - casa 5 - Taguatinga - DF - 72.125-080

(61) 8123-8541

fulviapr@gmail.com

Lívia Silva Mourão - turma F

QNL 21 - conjunto E - casa 16 - Taguatinga - DF - 72.152-105

(61) $9652-3545$

liviasmourao@gmail.com

2. Título: "A EJA no resgate da autoestima e na construção do cidadão crítico"

2.1 - Área de abrangência:

A área de abrangência será local.

2.2 - Caracterização da Instituição de Ensino

O Centro de Ensino Fundamental 11 de Taguatinga - CEF 11 - foi fundado em 14 de janeiro de 1966. Situa-se na CND 5 - Área Especial, Praça do Bicalho na zona urbana norte da cidade de Taguatinga e está vinculado à Secretaria de Estado de Educação do Distrito Federal - SEE/DF, cujo secretário, em junho do ano corrente, é Marcelo Aguiar dos Santos Sá e à Diretoria Regional de Ensino de Taguatinga - DRET, que tem à sua frente o diretor Francisco Rosa Filho.

Fazem parte de sua direção: Professora Cleonilde Pereira Pinheiro (diretora); Valdimir Silva Laet (supervisor administrativo); Acácio Lopes de Araujo (supervisor pedagógico) e Magnairta Gomes (secretária escolar). Participam também da direção quatro coordenadores pedagógicos, sendo um de cada área de conhecimento. $O$ cargo de vice-diretor está vago.

A instituição de ensino foi inaugurada em 1966 como Escola Classe 4 de Taguatinga, criada em 14 de janeiro de 1966, pelo Decreto № 481 do Governo do Distrito Federal.

Foi transformada em Centro de Ensino de 1ํ Grau 11 de Taguatinga pela Resolução №453 CD de 18 de fevereiro de 1981 e Parecer № 106 - CED, de 15 de setembro de 1982 - Diário Oficial do Distrito Federal № 184, de 5 de agosto de 1992

Por último, passou a ser Centro de Ensino Fundamental 11 de Taguatinga - CEF 111 após a publicação da Portaria 003, de 12 de janeiro de 2004.

O CEF 11 relaciona-se com muita dificuldade com a comunidade que o cerca. A praça é freqüentada por famílias, jovens e pessoas desconhecidas e desocupadas durante todo o dia. Os alunos da escola são perigosamente abordados por estranhos (usuários e traficantes de drogas, aliciadores para exploração sexual, gangues, entre outros), o que exige policiamento constante na área. 
Alguns eventos foram realizados na praça (desfiles, passeatas e outros movimentos) com o intuito de sensibilizar a comunidade local para prestigiar as atividades realizadas na escola, que refletem na sociedade.

Em 2007, a escola foi comunicada pelo Ministério da Educação que não havia atingido a nota mínima exigida pelo Índice de Desenvolvimento da Educação Básica - Ideb. Esse fato desencadeou momentos de reflexão e auto-avaliação, para que fosse possível encontrar meios para corrigir erros na metodologia, na avaliação, no estabelecimento de objetivos de cada disciplina e no foco das aulas.

Em 2008, a escola iniciou a execução do Plano de Desenvolvimento da Educação - PDE, sob a orientação da Diretoria Regional de Ensino de Taguatinga. Os profissionais discutem assuntos de interesse pedagógico e levantam dados que subsidiarão a construção de um Plano de Ação. Isto com o intuito de corrigir os índices relacionados a este estabelecimento de ensino com foco na aprendizagem significativa.

Hoje, a escola atende a duas modalidades de ensino: oferece as quatro séries finais do Ensino Fundamental, nos turnos matutino e vespertino e $1^{\circ}$ Segmento da Educação de Jovens e Adultos, no noturno. A comunidade escolar é composta por alunos das cidades de Ceilândia, Colônia Agrícola Samambaia, Riacho Fundo, Recanto das Emas, Samambaia, Santa Maria, Taguatinga, Vicente Pires e Águas Lindas de Goiás, caracterizando-a como uma instituição com rica diversidade sócioeconômica-cultural.

\section{3 - Características básicas do público-alvo:}

O público alvo é bastante heterogêneo, com faixa etária entre 15 e 60 anos, muitos são trabalhadores domésticos e da construção civil, outros prestam serviços gerais ou de vigilância em firmas terceirizadas.

3 - Justificativa e caracterização dos problemas

Dentre os problemas do nosso cotidiano como professor de Educação de Jovens e Adultos estão:

- 3.1 - A falta de ânimo, de motivação dos educandos jovens e adultos trabalhadores, que chegam para assistir às aulas, extenuados pela intensa jornada de trabalho. Seu ânimo, sua disposição estão embotados, necessitando de estímulo intenso e constante para perseverar nas atividades escolares que os capacitarão a novas perspectivas na vida. Dessa forma o projeto de intervenção local tem como proposta inicial a motivação para superação das dificuldades enfrentadas pelos alunos trabalhadores da EJA.

Torna-se imprescindível um esforço da comunidade escolar, como um todo, para despertar em cada aluno trabalhador o interesse em permanecer e aproveitar ao máximo a frequência na escola. $\mathrm{O}$ acolhimento desse aluno deve acontecer desde a sua entrada no portão da escola até o fim da aula. Esse processo de incentivo envolve a todos os membros da comunidade escolar. Aproveita- 
se toda a experiência e cultura que traz consigo o educando, levando-o a novas perspectivas do conhecimento.

É preciso dinamizar a autoestima, a automotivação, para que os "nãos" estabelecidos pelas condições desfavoráveis se tornem alavancas para a superação das tendências ao comodismo, à desistência e consequente evasão escolar.

Fazer com que nosso aluno tenha uma atitude resiliente, uma conduta positiva apesar das adversidades, ou seja, soma-se à resiliência a capacidade de construção positiva, superação, resignificação dos problemas, flexibilidade cognitiva.

- 3.2 - A dificuldade em realizar um trabalho verdadeiramente interdisciplinar que possa: ampliar a leitura crítica do mundo dos alunos, contribuir para superação do saber de senso comum pelo conhecimento mais crítico e possibilitar transformações reais nas condições de vida dos alunos.

O ser humano começa a conhecer o mundo por meio da família e progressivamente amplia o seu universo. A escola é uma das primeiras instâncias educativas e a partir dessa referência local nos inserimos na cidade, no país e no mundo. Para que o aluno possa ter noção de sua identidade de gênero, de etnia e de religiosidade, é preciso promover um encontro entre as informações que ele traz sobre sua vida, seus antepassados, sua história e construir uma perspectiva que vai do passado ao presente, contribuindo dessa forma para uma autoestima elevada do nosso educando, que passará a conhecer mais da sua própria história. O processo de percepção da construção da identidade permite ao educando compreender que ele faz e refaz sua história e a História.

Para melhor atender sua clientela, a Educação de Jovens e Adultos pode fazer com que as diferenças fortaleçam a humanização do processo ensino-aprendizagem, baseado em valores e crenças democráticas e que promova a diversidade e o pluralismo cultural.

Acreditamos que a integração da comunidade escolar, do Estado, da sociedade civil e do empresariado é necessária para implementação dos dispositivos constitucionais previstos no artigo 208 da Constituição Federal de 1988 e ampliação desses direitos, com a universalização da educação básica:

Artigo 208 - O dever do Estado com a educação será efetivado mediante a garantia de:

I - ensino fundamental, obrigatório e gratuito, inclusive para os que a ele não tiveram acesso na idade própria.

VII - atendimento ao educando, no ensino fundamental, através de programas suplementares de material didático-escolar, transporte, alimentação e assistência à saúde.

No artigo, "Educação de Jovens e Adultos: problemas e perspectivas", José E. Romão destaca: "Não há, na História da Educação Mundial, qualquer país que tenha tido sucesso na universalização da educação básica de seu povo, que não a tenha estendido o acesso e a conclusão, com sucesso, a todas as faixas etárias de sua população, estivessem elas na idade própria ou não para esse nível de escolaridade. Por outro lado, existem sobejas provas sobre a contribuição da universalização da educação básica escolarizada para a diminuição da mortalidade infantil, para a elevação da taxa média de vida, para a produtividade do sistema econômico, para socialização dos processos políticos decisórios..." 
4 - Objetivos gerais

- Promover a colaboração mútua, em que educandos sejam motivados, estimulados a vencerem as intempéries do dia-a-dia daqueles que trabalham e estudam.

- Provocar a leitura crítica do mundo dos alunos, contribuir para superação do saber de senso comum pelo conhecimento mais crítico e possibilitar transformações reais nas condições de vida dos alunos.

\section{5 - Objetivos específicos}

- Desenvolver situações que despertem o interesse, resgatem o ânimo e a motivação desses jovens e adultos.

- Identificar as dificuldades enfrentadas pelo alunos para continuarem os estudos, e buscar meios de minimizá-las ou até mesmo solucioná-las.

- Desenvolver atividades pedagógicas que valorizem o conhecimento dos educandos, respeitem a diversidade e promovam a reflexão e o pensamento crítico.

6 - Atividades/responsabilidades

- Apresentação do Projeto de Intervenção Local à equipe diretiva, à equipe de coordenação pedagógica e ao corpo docente da escola. Isso porque, o PIL foi construído em 2009, quando atuávamos no 2 o Segmento da EJA, no Centro de Ensino Médio de Taguatinga Norte. Em 2010, o PIL foi adaptado à realidade o $1^{\circ}$ Segmento da EJA, no Centro de Ensino Fundamental 11 de Taguatinga.

- Definição de um Pacto de Convivência entre todos os membros da comunidade escolar. Entre os itens do pacto destacamos:
a) Acolhimento
b) Tratamento respeitoso entre todos os membros da comunidade escolar.
c) Observância do horário das aulas.
d) Justificativa das faltas.
e) Cooperação na execução das atividades propostas pelo coletivo.
f) Cuidados com o uso do telefone celular nas dependências da escola.
g) Respeito ao patrimônio público.

- Realização de dinâmicas que visem o estímulo motivacional.

- Leitura, compreensão e interpretação de diversas tipologias textuais: história em quadrinhos, contos, crônicas, anúncios publicitários, bem como de diversos produtos áudio visuais: peças publicitárias, filmes curtas e filmes longas. As sinopses estão no Anexo.

7 - Cronograma

O Projeto de Intervenção Local será executado entre abril e julho de 2010.

8 - Parceiros

Comunidade escolar do Centro de Ensino Fundamental 11 de Taguatinga. 
9 - Orçamento

\begin{tabular}{|c|c|c|c|}
\hline № & ITEM & VALOR & OBSERVAÇÃO \\
\hline 1 & Locação de filme & $\mathrm{R} \$ 2,00$ cada & \\
\hline 2 & Ingredientes para salada de grãos & $R \$ 100,00$ & \\
\hline 3 & Pão integral & $\mathrm{R} \$ 15,90$ & \\
\hline 4 & Suco de frutas natural & $R \$ 19,00$ & \\
\hline 5 & Ingresso para o Circo & $\mathrm{R} \$ 5,00$ & $\begin{array}{l}\text { Os alunos que } \\
\text { puderam pagaram o } \\
\text { mesmo valor. Os } \\
\text { professores custearam } \\
\text { os ingressos dos } \\
\text { alunos que não têm } \\
\text { dinheiro. }\end{array}$ \\
\hline 6 & Reprodução dos textos & 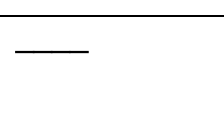 & $\begin{array}{l}\text { Ficou a cargo do CEF } \\
11 .\end{array}$ \\
\hline
\end{tabular}

10 - Acompanhamento e avaliação

Em fevereiro de 2010, a professora Fúlvia assumiu uma turma do $3^{\circ}$ Semestre e uma turma do 4 - Semestre do $1^{\circ}$ Segmento de Educação de Jovens e Adultos, no Centro de Ensino Fundamental 11 de Taguatinga. Em março de 2010, apresentamos o Projeto de Intervenção Local à equipe diretiva e à equipe de coordenação pedagógica da escola e fizemos as adaptações necessárias.

O projeto foi bem recebido pelos professores, mas é difícil colocá-lo em prática, porque não há um horário de coordenação pedagógica coletiva na escola. A comunicação entre professores começou a ser efetivada, em abril quando muitos docentes ingressaram no curso "Construindo Práticas Educativas na Modalidade EJA: Concepções Teórico-Metológicas”, promovido pela Escola de Aperfeiçoamento dos Profissionais da Educação - EAPE - e a proximidade da Semana da Educação para a Vida, evento que consta no calendário escolar 2010. Em reunião junto à equipe diretiva da escola, o corpo docente definiu a realização de coordenação pedagógica coletiva mensal, a partir do segundo semestre de 2010.

Nosso trabalho foi de verificar as conexões existentes entre o currículo escolar, a realidade dos alunos e obras textuais diversas. Assim, o educando sente-se motivado a aprender, a compartilhar suas experiências, a refletir sobre outros pensamentos, outras realidades.

O relato dos alunos mostra que estamos iniciando de maneira positiva. Eles não temem expressar seus pensamentos a respeito de questões importantes como: formação do povo brasileiro, discriminação racial, machismo e exploração dos trabalhadores. 


\begin{tabular}{|c|c|c|c|}
\hline № & TEMAS & ATIVIDADES & OBSERVAÇÕES \\
\hline 1 & Socialização & Dinâmica: Minha bandeira & \\
\hline 2 & Pacto de Convivência & Construção coletiva de regras e painel & \\
\hline 3 & $\begin{array}{l}\text { Expectativas dos } \\
\text { alunos em relação a } \\
\text { EJA }\end{array}$ & $\begin{array}{l}\text { Leitura, compreensão e interpretação de } \\
\text { história em quadrinhos. }\end{array}$ & \\
\hline 4 & $\begin{array}{l}\text { A questão de gênero } \\
\text { na } \\
\text { brasileira }\end{array}$ & $\begin{array}{l}\text { - Leitura, compreensão e interpretação do } \\
\text { texto "Mulheres do Brasil", Martha } \\
\text { Medeiros. } \\
\text { - Leitura, compreensão e interpretação de } \\
\text { folder da cerveja Devassa. } \\
\text { - Leitura, compreensão e interpretação de } \\
\text { trechos da Lei no } 11.340 / 2006 \text {, Lei Maria da } \\
\text { Penha }\end{array}$ & $\begin{array}{l}\text { O último item foi } \\
\text { desenvolvido } \\
\text { orientadora } \\
\text { educacional. }\end{array}$ \\
\hline 5 & $\begin{array}{l}\text { Saúde e qualidade de } \\
\text { vida }\end{array}$ & $\begin{array}{l}\text { - Conversa informal. } \\
\text { - Textos do livro didático. } \\
\text { - Campanhas educativas de combate à } \\
\text { Dengue e à Influenza H1N1. } \\
\text { - Jogos educativos sobre os cuidados com } \\
\text { a saúde. }\end{array}$ & \\
\hline 6 & $\begin{array}{l}\text { Formação do povo } \\
\text { brasileiro }\end{array}$ & $\begin{array}{l}\text { - Conversa informal. } \\
\text { - Leitura, compreensão e interpretação de } \\
\text { textos do livro didático. } \\
\text { - Músicas: "Chegança", de Antônio } \\
\text { Nóbrega e Wilson Freire e "100 anos de } \\
\text { liberdade, realidade ou ilusão" } \\
\text {, de Hélio Turco, Alvinho e Jurandir da } \\
\text { Mangueira. } \\
\text { - Leitura, compreensão e interpretação do } \\
\text { folder "Índio, cidadão brasileiro". } \\
\text { - Filme: "Carlota Joaquina, de Carla } \\
\text { Camurati. } \\
\text { - Poema: Canção dos Povos", de Tolba } \\
\text { Phanem. } \\
\text { - Confecção de cartazes sobre a } \\
\text { diversidade do povo brasileiro. } \\
\text { - Lanche de confraternização. }\end{array}$ & $\begin{array}{l}\mathrm{O} \text { lanche foi feito pelos } \\
\text { alunos e professores. }\end{array}$ \\
\hline 7 & Distrito Federal & $\begin{array}{l}\text { - Conversa informal. } \\
\text { - Compilação de textos informativos. } \\
\text { - Mapas } \\
\text { - Leitura, compreensão e interpretação: do } \\
\text { significado do substantivo candango; dos } \\
\text { comentários de Leunam sobre o filme } \\
\text { "Conterrâneos Velhos de Guerra, de } \\
\text { Vladimir de Carvalho e da música } \\
\text { "Cidadão", de Zé Ramalho. }\end{array}$ & \\
\hline 8 & Orientação espacial & $\begin{array}{l}\text { - Conversa informal. } \\
\text { - Compilação de textos informativos. } \\
\text { - Leitura crítica do mapa do Distrito Federal } \\
\text { e de nova proposta de divisão para o DF. }\end{array}$ & \\
\hline 9 & Sistema Digestório & $\begin{array}{l}\text { - Levantamento sobre os hábitos } \\
\text { alimentares dos alunos. } \\
\text { - Visionamento e estudo de figuras } \\
\text { representativas do sistema digestivo. } \\
\text { - Leitura, compreensão e interpretação de } \\
\text { compilação de textos informativos. } \\
\text { - Prevenção de doenças do sistema } \\
\text { digestório. }\end{array}$ & \\
\hline
\end{tabular}




\begin{tabular}{|c|c|c|c|}
\hline & & $\begin{array}{l}\text { - Confecção de cartazes. } \\
\text { - Jogos educativos. }\end{array}$ & \\
\hline 10 & $\begin{array}{l}\text { Características } \\
\text { geográficas } \\
\text { históricas do Brasil } \\
\text { As regiões brasileiras } \\
\text { O Brasil na América } \\
\text { do Sul }\end{array}$ & $\begin{array}{l}\text { - Leitura, compreensão e interpretação de } \\
\text { compilação de textos informativos. } \\
\text { - Mapas }\end{array}$ & \\
\hline 11 & $\begin{array}{lr}\text { As questões } & \text { de } \\
\text { trabalho, gênero } & \mathrm{e} \\
\text { étnico-raciais. } & \end{array}$ & $\begin{array}{l}\text { - Leitura, compreensão e interpretação dos } \\
\text { textos: "Domésticas sem cidadania", de } \\
\text { Sarita Coelho, "Pobreza extrema é coisa de } \\
\text { mulher", de Ruth Aquino e da música } \\
\text { "Mama África", de Chico César. } \\
\text { - Leitura crítica de anúncios para Dias das } \\
\text { Mães. } \\
\text { - Confraternização: Lanche rico em fibras }\end{array}$ & $\begin{array}{l}\text { O lanche foi feito pelas } \\
\text { professoras Fúlvia e } \\
\text { Lívia. }\end{array}$ \\
\hline
\end{tabular}

\section{SEMANA DE EDUCAÇÃO PARA A VIDA}

\begin{tabular}{|c|c|c|}
\hline DIA & NOTURNO & RECURSOS \\
\hline $\begin{array}{c}\text { 10/05 } \\
\text { 2a FEIRA }\end{array}$ & $\begin{array}{l}\text { Atividades diversificadas em sala de aula - } \\
\text { Dinâmicas Interativas; } \\
\text { Palestra - Tema: "Direitos e Deveres do Empregado } \\
\text { Doméstico" - Palestrante: Professor Arimatéia }\end{array}$ & $\begin{array}{l}\text { Data show, vídeo, } \\
\text { microfone, caixa de } \\
\text { som, materiais diversos. }\end{array}$ \\
\hline $\begin{array}{c}\text { 11/05 } \\
\text { 3a FEIRA }\end{array}$ & Espetáculo no Circo Rakmer, no Tagua Parque. & $\begin{array}{l}\text { Materiais diversos, } \\
\text { ônibus. }\end{array}$ \\
\hline $\begin{array}{c}\text { 12/05 } \\
\text { 4a FEIRA }\end{array}$ & $\begin{array}{l}\text { Oficinas de Criatividade } \\
\text { Palestra - Tema: "Uso consciente do dinheiro" }\end{array}$ & $\begin{array}{c}\text { Data show, vídeo, } \\
\text { microfone, caixa de } \\
\text { som, materiais diversos. }\end{array}$ \\
\hline $\begin{array}{c}13 / 05 \\
5 \text { a FEIRA }\end{array}$ & $\begin{array}{l}\text { Exibição de Filme e debate com pipoca } \\
\text { Exibição do Filme: O Contador de Histórias. }\end{array}$ & $\begin{array}{l}\text { Data show, vídeo, } \\
\text { microfone, caixa de } \\
\text { som, materiais diversos. }\end{array}$ \\
\hline $\begin{array}{l}\text { 14/05 } \\
\text { 6a FEIRA }\end{array}$ & $\begin{array}{l}\text { Atividades diversificadas em sala de aula: regras de boa } \\
\text { convivência e regimento interno. } \\
\text { Avaliação da Semana de Educação para a Vida. }\end{array}$ & Materiais diversos \\
\hline
\end{tabular}




\section{REFERÊNCIAS BIBLIOGRÁFICAS}

FREIRE, Paulo. Pedagogia do Oprimido. 22ª edição. Rio de Janeiro: Editora Paz e Terra.

GADOTTI, Moacir. Romão, José E. Educação de Jovens e Adultos: teoria, prática e proposta. São Paulo: Cortez Instituto Paulo Freire, 2008.

IBE - Instituto Brasileiro de Educação - Práticas Dinâmicas de Leitura e Escrita em Sala de Aula. Manual do Multiplicador. Brasília: Ministério da Saúde, 1997.

MARTINS, Leila Chalub. Ações afirmativas na UnB: o compromisso da extensão. Participação: Revista do Decanato de Extensão da Universidade de Brasília. Brasília: v.7, no 12, p 20-25, 2003.

TAVARES, José. Resiliência e educação. São Paulo: Cortez, 2001

TILLMAN, Diane. Atividades com Valores para Jovens.São Paulo: Confluência, 2003.

VÓVIO, Cláudia Lemos. IRELAND, Timothy Denis. Construção coletiva: contribuições à Educação de Jovens e Adultos. Brasília: UNESCO,MEC, RAAAB, 2008.

http://mensagensepoemas.uol.com.br/pensamentos/incentivo/avance-sempre.html\#ixzzOrUyFTq8a 


\section{ANEXOS}

\section{TEXTOS MOTIVACIONAIS}

1- Avance Sempre (autor desconhecido)

2- A Canção dos Homens (Tolba Phanen)

3- Acreditar e Agir (autor desconhecido)

4- Você pode (Luis Borges)

\section{ACREDITAR E AGIR}

Um viajante ia caminhando em solo distante, às margens de um grande lago de águas cristalinas. Seu destino era a outra margem.

Suspirou profundamente enquanto tentava fixar o olhar no horizonte. A voz de um homem coberto de idade, um barqueiro, quebrou o silêncio momentâneo, oferecendo-se para transportá-lo.

O pequeno barco envelhecido, no qual a travessia seria realizada, era provido de dois remos de madeira de carvalho.

Logo seus olhos perceberam o que pareciam ser letras em cada remo. Ao colocar os pés empoeirados dentro do barco, o viajante pode observar que se tratava de duas palavras, num deles estava entalhada a palavra ACREDITAR e no outro AGIR.

Não podendo conter a curiosidade, o viajante perguntou a razão daqueles nomes originais dados aos remos. O barqueiro respondeu pegando o remo chamado ACREDITAR e remou com toda força. $O$ barco, então, começou a dar voltas sem sair do lugar em que estava. Em seguida, pegou o remo AGIR e remou com todo vigor. Novamente o barco girou em sentido oposto, sem ir adiante.

Finalmente, o velho barqueiro, segurando os dois remos, remou com eles simultaneamente e o barco, impulsionado por ambos os lados, navegou através das águas do lago chegando ao seu destino, à outra margem.

Então o barqueiro disse ao viajante:

- Esse porto se chama autoconfiança. Simultaneamente, é preciso ACREDITAR e também AGIR para que possamos alcançá-lo!

Autor: desconhecido 


\section{AVANCE SEMPRE}

Na vida as coisas, às vezes, andam muito devagar.

Mas é importante não parar.

Mesmo um pequeno avanço na direção certa já é um progresso, e qualquer um pode fazer um pequeno progresso.

Se você não conseguir fazer uma coisa grandiosa hoje, faça alguma coisa pequena.

Pequenos riachos acabam convertendo-se em grandes rios.

Continue andando e fazendo.

O que parecia fora de alcance esta manhã vai parecer um pouco mais próximo amanhã ao anoitecer se você continuar movendo-se para frente.

A cada momento intenso e apaixonado que você dedica a seu objetivo, um pouquinho mais você se aproxima dele.

Se você pára completamente é muito mais difícil começar tudo de novo.

Então continue andando e fazendo. Não desperdice a base que você já construiu. Existe alguma coisa que você pode fazer agora mesmo, hoje, neste exato instante. Pode não ser muito mas vai mantê-lo no jogo.

Vá rápido quando puder.

Vá devagar quando for obrigado.

Mas, seja, lá o que for, continue.

O importante é não parar!!!

\section{VOCÊ PODE}

Autor: Luis Borges

Você pode curtir ser quem você é, do jeito que você for, ou viver infeliz por não ser quem você gostaria.

Você pode assumir sua individualidade, ou reprimir seus talentos e fantasias, tentando ser o que os outros gostariam que você fosse.

Você pode produzir-se e ir se divertir, brincar, cantar e dançar, ou dizer em tom amargo que já passou da idade ou que essas coisas são fúteis sérias e bem situadas como você. 
Você pode olhar com ternura e respeito para si próprio e para as outras pessoas, ou com aquele olhar de censura, que poda, pune, fere e mata, sem nenhuma consideração para com os desejos, limites e dificuldades de cada um inclusive os seus.

Você pode amar e deixar-se amar de maneira incondicional, ou ficar se lamentando pela a falta de gente à sua volta.

Você pode ouvir o seu coração e viver aproximadamente ou agir de acordo com o figurino da cabeça, tentando analisar e explicar a vida antes de vivê-la.

Você pode deixá-la como está para ver como é que fica ou com paciência e trabalho conseguir realizar as mudanças necessárias na sua vida e no mundo à sua volta.

Você pode deixar que o medo de perder paralise seus planos ou partir para a ação com o pouco que tem e muita vontade de ganhar.

Você pode amaldiçoar sua sorte, ou encarar a situação como uma grande oportunidade de crescimento que a Vida the oferece.

Você pode mentir para si mesmo, achando desculpas e culpados para todas as suas insatisfações, ou encarar a verdade de que, no fim das contas, sempre você é quem decide o tipo de vida que quer levar.

Você pode escolher o seu destino e, através de ações concretas caminhar firme em direção a ele, com marchas e contramarchas, avanços e retrocessos, ou continuar acreditando que ele já estava escrito nas estrelas e nada mais lhe resta a fazer senão sofrer.

Você pode viver o presente que a Vida Ihe dá, ou ficar preso a um passado que já acabou - e, portanto não há mais nada a fazer -, ou a um futuro que ainda não veio - e que, portanto não lhe permite fazer nada.

Você pode ficar numa boa, desfrutando o máximo de coisas que você é e possui, ou se acabar de tanta ansiedade e desgosto por não ser ou não possuir tudo o que você gostaria.

Você pode engajar-se no mundo, melhorando a si próprio e, por conseqüência, melhorando tudo que está à sua vota, ou esperar que o mundo melhore para que então você possa melhorar.

Você pode celebrar a Vida e a Energia Universal que o criou, ou celebrar a morte, aterrorizado com a idéia de pecado e punição.

Você pode continuar escravo da preguiça, ou comprometer-se com você mesmo e tomar atitudes 
necessárias para concretizar o seu Plano de Vida.

Você pode aprender o que ainda não sabe, ou fingir que já sabe tudo e não precisa aprender nada mais.

Você pode ser feliz com a vida como ela é, ou passar todo o seu tempo se lamentando pelo que ela não é.

A escolha é sua.

E o importante, é que você sempre tem escolha.

Pondere bastante ao se decidir, pois é você que vai carregar - sozinho e sempre - o peso das escolhas que fizer.

\section{DINÂMICAS}

\section{1 - BANDEIRA PESSOAL}

Objetivos:

Possibilitar aos participantes a identificação das suas habilidades e limitações.

Material:

Folhas de papel A4, lápis preto, lápis de cor, borrachas.

Como Fazer:

1. Dar a cada participante uma folha de papel A4. Distribuir o material de desenho pela sala.

2. Explicar ao grupo que a bandeira geralmente representa um país e significa algo da história desse país. Nesta atividade cada um vai construir sua própria bandeira a partir de seis perguntas feitas pelo orientador.

3. Pedir que respondam a cada pergunta por intermédio de um desenho ou de um símbolo na área adequada. Os que não quiserem desenhar poderão escrever uma frase ou algumas palavras, mas o orientador deve procurar incentivar a expressão pelo desenho.

4. O orientador faz as seguintes perguntas:

a) Qual o seu maior sucesso individual?

b) O que gostaria de mudar em você?

c) Qual a pessoa que você mais admira?

d) Em que atividade você se considera muito bom?

e) O que mais valoriza na vida?

f) Quais as dificuldades ou facilidades para se trabalhar em grupo?

Dar cerca de vinte minutos para que a bandeira seja confeccionada.

5. Quando todos tiverem terminado, pedir que formem pequenos grupos e compartilhem suas bandeiras.

6. Abrir a grande roda para comentar o que mais chamou a atenção de cada um em sua própria bandeira e na dos companheiros. Contar o que descobriu sobre si mesmo e sobre o grupo.

7. No fechamento do encontro, cada participante diz como se sente após ter compartilhado com o grupo sua história pessoal.

Comentários:

1. Tomar consciência das suas habilidades e limitações propicia um conhecimento mais aprofundado 
sobre si mesmo, suas habilidades, facilitando as escolhas que precisa fazer na vida.

2. Feita dessa forma, a reflexão torna-se prazerosa, evitando resistências.

\section{2 - PROJETO DE VIDA}

Sonhos, desejos, metas e desafios são importantes e necessários no "Projeto de Vida" de todos nós.

VAMOS PLANEJAR

( ) Acordar sorrindo.

( ) Aproveitar mais os dia de sol.

( ) Conversar mais com a minha família.

( ) Passar mais tempo com quem gosto.

( ) Não começar a fumar.

( ) Parar de fumar. Definitivamente.

( ) Mentir menos que no ano passado.

( ) Ser menos ciumento.

( ) Parar de ficar falando da vida dos outros.

( ) Devolver tudo o que pedir emprestado.

( ) Pedir de volta tudo o que emprestei.

( ) Resolver as coisaS da maneira menos complicada.

( ) Saber a hora de parar.

( ) Dizer bom dia, boa tarde, boa noite para todo mundo.

( ) Lembrar dos aniversários de todo mundo.

( ) Melhorar a minha caligrafia.

( ) "Entrar menos em roubadas".

( ) Ser menos preguiçoso (a).

( ) Contar segredos apenas para os amigos.

( ) Pensar antes de falar.

( ) Não prometer o que não dá para cumprir.

( ) Acordar sempre com o pé direito.

( ) Não fazer besteiras para não me arrepender.
( ) Curtir os finais de semana com responsabilidade.

( ) Fazer novos amigos.

( ) Não esquecer os velhos amigos.

( ) Falar menos ao celular. Principalmente na sala de aula.

( ) Ser mais organizado.

( ) Economizar mais água. Principalmente na hora do banho.

( ) Falar mais com Deus.

( ) Chorar quando tiver vontade.

( ) Dizer sim à vida.

( ) Não imitar as pessoas e ser mais autêntico.

( ) Atravessar na faixa de pedestre.

( ) Falar menos e fazer mais.

( ) Perguntar ao professor tudo que não entender.

( ) Assumir quando errar e pedir desculpas.

( ) Acabar com o chulé, por bem ou por mal.

( ) Fazer apenas críticas construtivas.

( ) Não falar alto na sala de aula.

( ) Melhorar o humor.

( ) Não ter medo de mudar de idéia.

( ) Ajudar e pedir ajuda nos estudos.

( ) Dizer não ao preconceito e à violência. 


\section{3 - EDUCAÇÃO DE JOVENS E ADULTOS \\ AVALIANDO NOSSA SEMANA \\ 10/05/10 À 14/05/10}

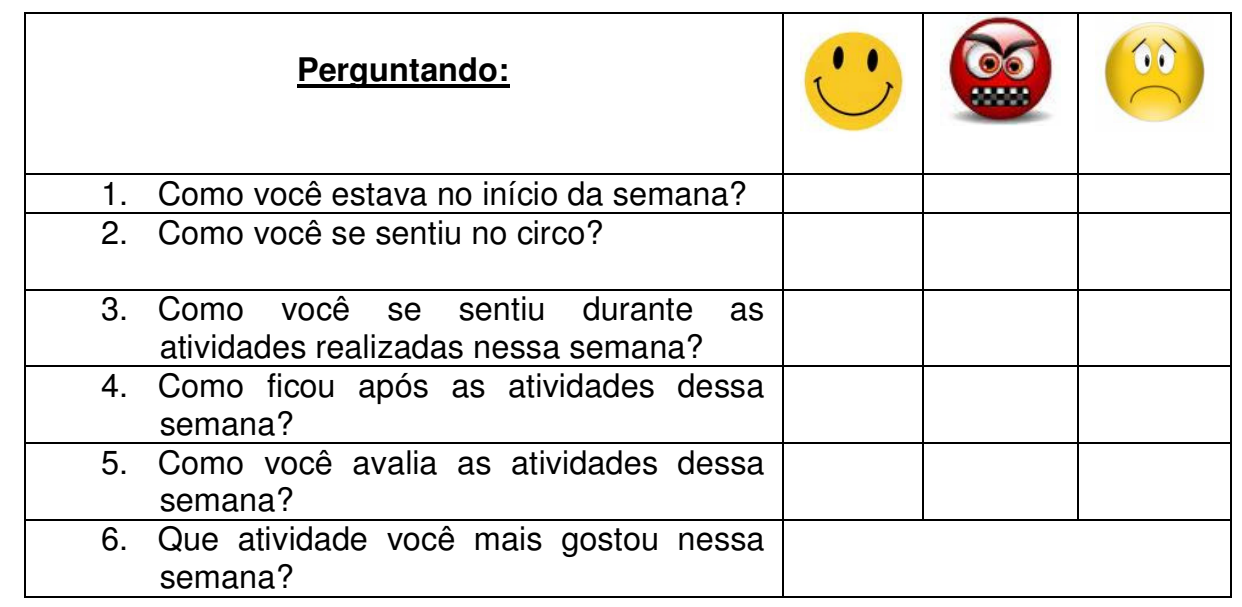

\section{Turma:}

Professora:

\section{TEXTOS}

\section{1 - Candangos}

1 - Leia os significados da palavra candango no Dicionário Houaiss da Língua Portuguesa

candango - substantivo masculino

a) nome que os africanos davam aos portugueses (galego)

b) indivíduo desprezível

c) nome que designa cada um dos operários que trabalharam nas grandes construções da cidade de Brasília (DF), geralmente oriundos do Nordeste do Brasil

2 - Leia o comentário de Leunam sobre o filme "Conterrâneos Velhos de Guerra", dirigido por Vladimir de Carvalho.

\section{Conterrâneos Velhos de Guerra}

Por blogdoleunam

Assisti ao documentário "Conterrâneos Velhos de Guerra", onde foi apresentado o outro lado da construção de Brasília. Contando com a participação do construtor da nova capital federal, Oscar Niemeyer, o documentário foi produzido em 1990 e mostra a face cruel do capitalismo e da forma como foram tratados os operários, trabalhadores braçais, após a construção do Distrito Federal.

Fazendo um contexto com a música "Cidadão", de Zé Ramalho, tão logo os edifícios e os palácios do Planalto foram levantados, os homens que o construíram, juntamente com suas esposas e filhos, foram expulsos do local e mandados para um lugar que ficava a 35 quilômetros do luxo de Brasília, a cidade satélite chamada Ceilândia. Um dos trabalhadores civis da época fez o seguinte 
depoimento: "nós servimos apenas até o término da obra. Depois fomos tratados que nem cachorro, jogados no mato debaixo de chuva. Eu, minha mulher e meus nove filhos ficamos dentro de um lugar que parecia um caixote. E até hoje nem consegui ainda me aposentar". E foram centenas de trabalhadores da construção civil que perderam suas vidas durante a obra, sem contar os assassinatos promovidos pela própria Polícia - segundo o documentário - como naquela manhã onde mais de 40 operários foram baleados e mortos. Sabem por quê? Porque reivindicavam uma alimentação adequada a um ser humano, pois em seus pratos de comida vinham restos de baratas, moscas e outras porcarias.

Esta longa e triste sina dos retirantes nordestinos que deixaram suas terras e viajaram até a região Centro-Oeste do Brasil para fazer realizar um sonho do então presidente JK, nos faz refletir sobre a discriminação e as injustiças sociais que são impostas contras as classes mais humildes. Ali, na construção da capital federal - conforme citou o próprio Niemeyer - o grande problema foi justamente a diferença de classes. Infelizmente, para se realizar os sonhos de alguns, maltratam outros tantos mais.

3 - Leia a letra da música "Cidadão", de Zé Ramalho.

Tá vendo aquele edifício moço

Ajudei a levantar

Foi um tempo de aflição, era quatro condução

Duas pra ir, duas pra voltar

Hoje depois dele pronto

Olho pra cima e fico tonto

Mas me vem um cidadão

E me diz desconfiado

"Tu tá aí admirado ou tá querendo roubar"

Meu domingo tá perdido, vou pra casa entristecido

Dá vontade de beber

E pra aumentar meu tédio

Eu nem posso olhar pro prédio que eu ajudei a fazer

Tá vendo aquele colégio moço

Eu também trabalhei lá

Lá eu quase me arrebento

Fiz a massa, pus cimento, ajudei a rebocar

Minha filha inocente veio pra mim toda contente

"Pai vou me matricular"

Mas me diz um cidadão:

"Criança de pé no chão aqui não pode estudar"

Essa dor doeu mais forte

Porque que é qu'eu deixei o norte 
Eu me pus a me dizer

Lá a seca castigava, mas o pouco que eu plantava

Tinha direito a colher

Tá vendo aquela igreja moço, onde o padre diz amém

Pus o sino e o badalo, enchi minha mão de calo

Lá eu trabalhei também

Lá foi que valeu a pena, tem quermesse, tem novena

E o padre me deixa entrar

Foi lá que Cristo me disse:

"Rapaz deixe de tolice, não se deixe amedrontar

Fui eu quem criou a terra

Enchi o rio, fiz a serra, não deixei nada faltar

Hoje o homem criou asas e na maioria das casas

Eu também não posso entrar"

\title{
2 - Domésticas sem cidadania
}

\begin{abstract}
Assédio moral e sexual, preconceito e desrespeito fazem parte da rotina das empregadas, diz pesquisa da UnB
\end{abstract}

Sarita Coelho

É na internet, sob proteção do anonimato ou de identidades falsas, que o preconceito contra empregadas domésticas se manifesta de forma mais aberta. Nas quase 700 comunidades dedicadas a elas no site de relacionamento Orkut, internautas contam, em tom de piada, as situações de xingamento, de acusações mentirosas de roubo e de assédio sexual das quais suas empregadas já foram vítimas.

Histórias como essas fazem parte de uma realidade compartilhada pela maioria das domésticas brasileiras, especialmente as negras, como mostra uma tese de doutorado defendida na Universidade de Brasília (UnB). A antropóloga Dora Porto analisou mais de 100 variáveis ligadas à qualidade de vida de mulheres negras com idade entre 13 e 63 anos. Por coincidência, todas já tinham trabalhado como domésticas ou eram filhas de empregadas.

O estudo mostrou que, de forma geral, essas trabalhadoras assumem muito cedo a responsabilidade da casa e temem o desemprego. Por isso, muitas aceitam as ofensas verbais e os vínculos empregatícios precários. Esse é o caso da doméstica Vera Lúcia Barros, 30 anos, que nunca trabalhou com carteira assinada em dez anos de profissão. "Meus contratos sempre foram de boca. Quem está precisando, não pensa nesses detalhes", revela.

SILÊNCIO - Por medo da demissão, elas também optam por não entregar aos patrões atestados médicos e mantêm seus afazeres mesmo doentes; aceitam o ritmo pesado de trabalho, 
muitas vezes com uma carga superior a 12 horas diárias e evitam tirar férias. "Esses problemas existem aos montes, mas ficam no silêncio porque muitas empregadas têm medo de procurar a justiça", confirma o presidente do Sindicato dos Trabalhadores Domésticos do Distrito Federal, Antônio Barros.

Para a antropóloga, é curioso que a maioria das patroas negue a existência desse tipo de relação com as empregadas. "Quando contava o resultado da pesquisa para conhecidos meus e a tendência natural era ouvir a defesa dos patrões", lembra Dora. As histórias falavam de roubos cometidos por empregadas e de amizades surgidas entre elas e as patroas, situações também comum. No entanto, ela acredita que esses fatos não podem ser usados como desculpa para ignorar os abusos. "É preciso deixar a hipocrisia de lado, dar visibilidade para a situação e estimular a criação de políticas públicas voltadas para as mulheres", defende a especialista.

Dora também chama atenção para um problema comum no passado, mas ainda existente em algumas casas brasileiras: trabalho doméstico infantil. Uma das idosas entrevistadas na pesquisa foi levada para trabalhar numa casa de família. Ela foi responsável por todo serviço doméstico: cuidar de três crianças, cozinhar, lavar roupa e até mesmo passá-las, o que, naquela época, implicava no uso de ferro a carvão.

\section{NÚMEROS}

$>$ Existem aproximadamente 8 milhões de empregados domésticos no Brasil, o que corresponde a toda população de Pernambuco.

$>95 \%$ deles são mulheres.

$>82 \%$ das mulheres são negras.

> Quase 500 mil crianças e adolescentes entre 5 e 17 anos estão no trabalho doméstico.

$>$ Essa classe de trabalhadores recebe apenas 35\% da renda média de todos os trabalhadores.

$>27,5 \%$ não chegam a receber um salário mínimo por mês.

$>$ Apenas $26 \%$ têm carteira assinada.

$>$ Menos de $2 \%$ deles são sindicalizados.

> O trabalho dos empregados domésticos é regularizado desde 1972, com a publicação da Lei № 5.859 .

$>$ O Brasil foi condenado uma vez por discriminação racial pela Organização dos Estados Americanos (OEA) porque não investigou o caso da doméstica Simone Diniz, que foi impedida de participar de uma seleção de emprego por ser negra.

\section{"Não trabalho mais em casa de família"}

As experiências negativas na vida de Silmara Alves de Souza, 35 anos, a fizeram desistir do trabalho doméstico. Hoje, como recepcionista, ela até admite ganhar menos que uma babá. Mas, para "casa de família", ela não volta. Uma de suas ex-patroas não a deixava pegar o 
filho pequeno. O motivo era simples: a empregada usava hospital público e poderia passar alguma infecção para o bebê.

Em outra casa, Silmara era xingada pelas crianças. A patroa não acreditava que seus filhos fizessem tais grosseiras. A doméstica tinha uma jornada de 12 horas, só podia comer a sobra do almoço e era proibida de abrir a geladeira. Depois de oito meses de sofrimento, não pensou duas vezes: abandonou o emprego.

\title{
Os direitos da empregada doméstica
}

Por não serem contemplados na Consolidação das Leis do Trabalho (CLT), os empregados domésticos não têm direito a feriados, isso acaba sendo negociado a critério dos patrões. Também não Ihes são asseguradas garantias como jornada de trabalho restrita a oito horas diárias; adicional noturno; salário-família, benefício para auxiliar no sustento dos filhos até 14 anos; Fundo de Garantia por Tempo de Serviço (FGTS); e o seguro-desemprego, que existe para proteger o trabalhador em caso de demissões sem justa causa.

Mas a Lei que ampara os trabalhadores domésticos (Lei ํㅜ 5.859) garante salário não inferior ao mínimo, uma folga por semana, preferencialmente aos domingos, férias anuais, adicional de férias, $13^{\circ}$ salário, licença maternidade, aviso prévio e vale-transporte.

Em setembro de 2006, foi sancionado o projeto de Lei relativo à Medida Provisória oㅡ 284, que garante aos trabalhadores domésticos 30 dias de férias anuais (antes eram 20). A lei também proíbe os patrões de descontar dos empregados custos de alimentação, uniforme, higiene e moradia e de demitir a doméstica grávida desde a confirmação da gravidez até cinco meses depois do parto. A lei estimula o empregador doméstico a contribuir com Instituto Nacional do Seguro Social (INSS), já que o valor agora pode ser descontado do Imposto de Renda.

Fonte: UnB Notícias - Ano 10, número 79 - maio e junho de 2007

\section{MÚSICAS}

1 - Cidadão, de Zé Ramalho. A letra consta no texto 1.

\section{2 - Mama África}

Chico César

\author{
Mama África (a minha mãe) \\ é mãe solteira \\ e tem que fazer \\ mamadeira todo dia \\ além de trabalhar \\ como empacotadeira
}




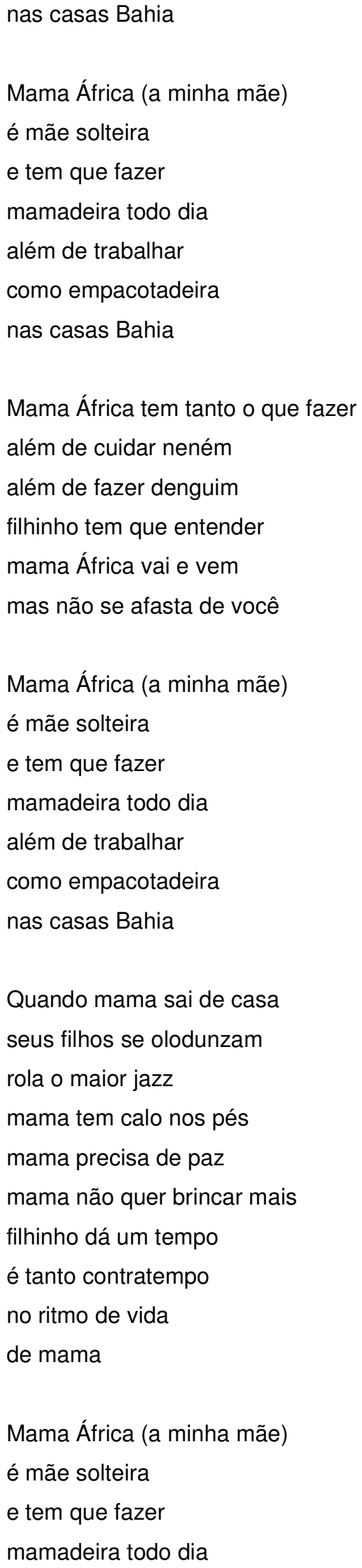




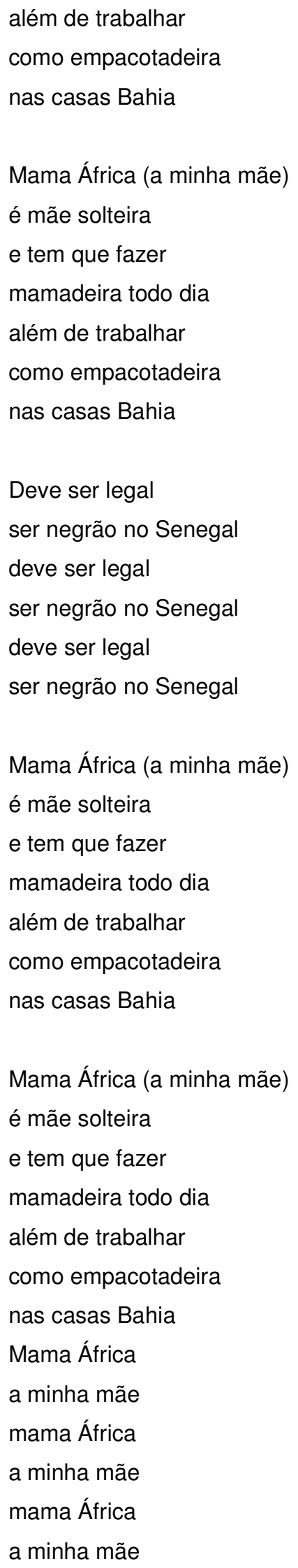




\section{FILMES - SINOPSES}

\section{1 - Carlota Joaquina}

Um painel da vida de Carlota Joaquina (Marieta Severo), a infanta espanhola que conheceu o príncipe de Portugal (Marco Nanini) com apenas dez anos e se decepcionou com o futuro marido. Sempre mostrou disposição para seus amantes e pelo poder e se sentiu tremendamente contrariada quando a corte portuguesa veio para o Brasil, tendo uma grande sensação de alívio quando foi embora.

Informações técnicas:

País de Origem: Brasil

Gênero: Comédia

Tempo de Duração: 104 minutos

Ano de Lançamento: 1995

Estúdio/Distribuição: Europa Filmes

Direção: Carla Camurati

\section{2 - O contador de histórias}

Baseado em fatos reais. Belo Horizonte, fim da década de 70. Aos 6 anos, Roberto Carlos Ramos já demonstra enorme talento para contar histórias. Caçula de dez irmãos e morador de favela, é o escolhido por sua mãe para ir viver numa nova instituição anunciada pelo governo como uma oportunidade para aqueles que viviam na pobreza.

Informações técnicas:

Título original: O Contador de Histórias

Gênero: Drama

Duração: 100 min.

Lançamento (Brasil): 2009

Distribuição: Warner Brothers

Direção: Luiz Villaça

Roteiro: Mauricio Arruda, José Roberto Torero, Mariana Veríssimo, Luiz Villaça 